Objective: To investigate whether endothelial monolayer permeability changes induced by inflammatory mediators are affected by the extracellular matrix protein used for cell seeding.

Methods: Human umbilical venular endothelial cells (HUVEC) were grown to confluent monolayers on membranes coated with either collagen, fibronectin or gelatin. The permeability to albumin and dextran was then assessed, both under normal conditions and after treatment with tumor necrosis factor-alpha (TNF- $\alpha$ ) and bacterial lipopolysaccharide (LPS).

Results: With any of the three protein coatings, tight junctions were formed all over the monolayers. The permeability of the coated membranes to albumin and dextran was reduced strongly by confluent monolayers; the relative reduction was similar for the three matrix proteins used. Pre-incubation of the monolayers with either TNF- $\alpha$ or LPS increased permeability dose dependently. However, the relative increase due to either treatment was independent of the protein used for membrane coating.

Conclusion: The extracellular matrix protein used for initial seeding of endothelial cultures plays a minor role in determining the permeability changes induced in HUVEC monolayers by inflammatory mediators.

Key words: Endothelium, Extracellular matrix (ECM), HUVEC, Inflammatory mediator, Tumor necrosis factor, endotoxin, monolayer permeability

\section{Permeability characteristics of human endothelial monolayers seeded on different extracellular matrix proteins}

\author{
Arjan Nooteboom, ${ }^{1}$ Thijs Hendriks, ${ }^{1, C A}$ \\ Irene Ottehöller ${ }^{2}$ and Cees. J. van der Linden ${ }^{1,3}$
}

Departments of ${ }^{1}$ Surgery and ${ }^{2}$ Pathology, University Medical Center Nijmegen, The Netherlands; ${ }^{3}$ present address: Department of Surgery, De Wever Hospital, Heerlen, The Netherlands

\author{
${ }^{\mathrm{CA}}$ Corresponding Authors \\ Tel: (+31) 24 3613983/3616420 \\ Fax: (+31) 243540501 \\ E-mail: t.hendriks@heel.azn.nl
}

\section{Introduction}

The vascular endothelium acts as a dynamic barrier that selectively restricts the passage of plasma and cells from the blood into the adjacent tissues. Local and reversible alterations of barrier function typically occur as part of the immune response during which inflammatory mediators cause a transient increase of vascular permeability resulting in the formation of tissue oedema. However, during systemic inflammatory response syndrome (SIRS), ${ }^{1}$ over-production of inflammatory mediators may irreversibly damage vascular integrity and cause excessive loss of fluid from the circulation. This hazardous event may lead to prolonged tissue hypoperfusion, organ dysfunction and death. ${ }^{2}$ Therefore, prevention of vascular damage could contribute to improved survival of patients suffering from SIRS. ${ }^{3,4}$ Many have studied the role of the endothelium in vascular permeability using in vitro models of endothelial monolayers cultured on semi-permeable supports. ${ }^{5-7}$ Multiple mechanisms may be involved in increased endothelial permeability, such as cell contraction and retraction, ${ }^{8}$ enhanced transcellular vesicle transport, ${ }^{9}$ disruption of intercellular junctions ${ }^{10}$ and apoptosis. ${ }^{11}$

Recently, it has been suggested that endothelial permeability may also depend on the composition and structure of the underlying extracellular matrix (ECM). ${ }^{12}$ For example, it has been shown that fibronectin significantly contributes to endothelial monolayer permeability by providing attachment sites for ECM proteins and endothelial cells. ${ }^{13}$ When monolayers cultured on fibronectin were treated with tumor necrosis factor- $\alpha$ (TNF- $\alpha)$, a permeability increase was observed which was accompanied by a loss of fibronectin from the ECM. ${ }^{14}$ TNF- $\alpha$ also affects the expression of other matrix receptors on endothelial cells, confirming a role for endothelial - ECM contacts in vascular permeability. ${ }^{15}$ Furthermore, stimulation of endothelial cells with TNF- $\alpha$ induced the expression of a $96-\mathrm{kDa}$ matrix metalloproteinase ${ }^{16}$ suggesting that matrix degradation may be involved in increased permeability. ${ }^{17}$

For the purpose of studying endothelial permeability in vitro, these findings seem to imply that endothelial cells should be cultured on (a mixture of) ECM proteins, preferably containing fibronectin, but other ECM coatings like gelatin and different types of collagen are used frequently. ${ }^{18}$ It remains unclear whether different coatings eventually result in different monolayer permeability changes under the influence of inflammatory mediators. A comparison of $i n$ vitro studies on endothelial permeability is hampered by the many differences in the origin and species of 
the endothelial cells and, particularly, by the differences in the design of the monolayer system, including the matrix used for cell seeding.

Therefore, we have compared the permeability characteristics of human umbilical venular endothelial cells (HUVEC) seeded on membranes coated with either collagen, fibronectin or gelatin. For this purpose, we have selected a suitable in vitro model that supports the attachment and growth of HUVEC, and allows restricted diffusion of macromolecules, visual examination by both bright field microscopy and ultramicroscopy, and easy and simultaneous permeability determinations. The inflammatory mediators TNF- $\alpha$ and bacterial lipopolysaccharide (LPS), which are involved in the onset of SIRS, have been shown to enhance endothelial permeability both in vivo and in vitro. ${ }^{19-22}$ We measured the permeability for both albumin and dextran in untreated HUVEC monolayers and in cultures after treatment with either TNF- $\alpha$ or LPS.

\section{Materials and methods}

Materials

Culture medium M199, supplemented with $25 \mathrm{mmol} / 1$ HEPES, Earl's salts and L-glutamine, as well as heatinactivated newborn calf serum (NCS), penicillinstreptomycin and trypsin/EDTA were obtained from Life Technologies (Paisley, Scotland). Normal human serum was supplied by a local transfusion service. A pool of serum of at least five donors was first heat inactivated $\left(30 \mathrm{~min}\right.$ at $\left.56^{\circ} \mathrm{C}\right)$, and stored at $-20^{\circ} \mathrm{C}$ before use. Transwell-well culture inserts, tissue culture plates and flasks were all from Costar (Cambridge, MA). Fluorescin-labelled bovine serum albumin (FITC-BSA), rhodamin-labelled dextran (RITC-DEX, mean molecular weight 70,000), collagenase type I (from Clostridium bystolyticum), pig skin gelatin (type A) and LPS (E. coli, strain 055:B5) were purchased from Sigma Chemical (St Louis, MO). Human fibronectin was obtained from Boehringer Mannheim (Mannheim, Germany). A crude fraction of endothelial cell growth factors (ECGF) was kindly provided by the Department of Pediatrics, University Hospital of Nijmegen, The Netherlands. Heparin was obtained from Leo pharmaceutical products (Weesp, The Netherlands). Recombinant human TNF- $\alpha(6 \times$ $10^{7} \mathrm{U} / \mathrm{mg}$, endotoxin content $<1 \mathrm{EU} / \mathrm{mg}$ ) was obtained from Bender \& Co, Vienna.

\section{Isolation and culture of HUVEC}

Endothelial cells were isolated according to a modification of the method described by Jaffe and coworkers. ${ }^{23}$ Upon delivery the umbilical cords were placed in sterile, ice cold cord buffer $(140 \mathrm{mmol} / 1$ $\mathrm{NaCl}, 4 \mathrm{mmol} / 1 \mathrm{KCl}, 11 \mathrm{mmol} / 1 \mathrm{D}$-glucose, $10 \mathrm{mmol} / 1$
HEPES, $100 \mathrm{IU}$ penicillin, and $0,1 \mathrm{mg} / \mathrm{ml}$ streptomycin, $\mathrm{pH} 7,3$ ) and stored at $4^{\circ} \mathrm{C}$ until use. In brief, the umbilical vein was rinsed with cord buffer to remove blood and debris from the lumen after which the vein was filled with medium M199 containing 0.1\% (w/v) collagenase. Endothelial cells were detached by incubation for $20 \mathrm{~min}$ at $37^{\circ} \mathrm{C}$ and harvested by collecting the collagenase solution. After centrifugation $(5 \mathrm{~min}$ at $300 \times g$ ), the cells were resuspended in complete medium (M199 with 10\% NCS, 10\% normal human serum, $50 \mathrm{U} / \mathrm{ml}$ penicillin, $50 \mu \mathrm{g} / \mathrm{ml}$ streptomycin, $150 \mu \mathrm{g} / \mathrm{ml}$ crude ECGF and $5 \mathrm{U} / \mathrm{ml}$ heparin) and seeded onto $0.1 \%$ gelatin-coated $25 \mathrm{~cm}^{2}$ culture flasks. The cultures were kept in a humidified incubator at $37^{\circ} \mathrm{C}$ under a $5 \% \mathrm{CO}_{2} / 95 \%$ air atmosphere. After one day, and then three times weekly, the culture medium was refreshed. Confluent cultures (typically yielding $10^{5}$ cells $/ \mathrm{cm}^{2}$ or more) were passaged by detaching the cells with $0.5 \mathrm{mg} / \mathrm{ml}$ trypsin and $0.2 \mathrm{mg} / \mathrm{ml}$ EDTA, which was followed by centrifugation and resuspension in complete medium. For appropriate growth, a split ratio of $1: 2$ or 1:3 was used. All experiments were performed on cells that had been passaged less than four times.

Endothelial origin of the cultures was confirmed by phase contrast microscopy, which revealed confluent cultures displaying a typical cobblestone morphology, while immunocytochemical analysis revealed positive staining for von Willebrand Factor and CD31 (platelet endothelial cell adhesion molecule (PECAM)-1). Activation with TNF- $\alpha$ or LPS-induced expression of intercellular adhesion molecule (ICAM)-1 and E-selectin (data not shown).

\section{Preparation of microporous membranes and cell seeding}

For permeability determinations, two different culture inserts were used, one containing a polyester (PE) membrane (Transwell Clear) and the other containing a collagen pre-treated polyethylene terephtalate (PTFE) membrane (Transwell COL). Both types of membrane contained $0.4 \mu \mathrm{m}$ diameter pores and a growth area of $1 \mathrm{~cm}^{2}$. However, differences existed in pore density and membrane thickness. While the PTFE membranes were obtained with a collagen (bovine, type I/III) coating in place, and thus were ready for culturing, the PE membranes were prepared for cell seeding by overnight incubation at room temperature with either fibronectin $\left(10 \mu \mathrm{g} / \mathrm{cm}^{2}\right)$, or gelatin $\left(10 \mu \mathrm{g} / \mathrm{cm}^{2}\right)$ in medium M199. No significant difference in permeability was observed between uncoated and coated PE membranes (data not shown).

The inserts were placed in 12-well culture plates, resulting in a two-compartment system separated by the membrane. Approximately $10^{5}$ cells $/ \mathrm{cm}^{2}$ in $0.5 \mathrm{ml}$ of complete medium were seeded at the upper side of the membrane, whereas $1.5 \mathrm{ml}$ of complete medium 
was added to the lower compartment. These volumes prevented hydrostatic fluid pressures across the membranes. Both compartments were frequently replenished with complete medium as described. Cultures were grown for six days, resulting in the formation of confluent monolayers, which was confirmed by phase contrast light microscopy.

In one experiment, the confluent cell layer was selectively removed from the membranes. This was achieved by briefly incubating the monolayers with a $25 \mathrm{mmol} / 1 \mathrm{NH}_{4} \mathrm{OH}$ solution. Removal of attaching cells from the membrane was confirmed by transmission electron microscopy examination.

\section{Transmission electron microscopy of HUVEC monolayers}

Cultured cells on Transwell inserts were washed twice with serum-free medium prior to fixation with $2 \%$ glutaraldehyde in phosphate-buffered saline (PBS). After $60 \mathrm{~min}$ of fixation the Transwells were washed with PBS and treated with $1 \% \mathrm{OsO}_{4}$ for $30 \mathrm{~min}$ and washed again with PBS. After several steps of dehydration, with 30\%-70\%-90\%-100\% alcohol, followed by 1:1 mix, 1:2 mix and pure epon 812, the membranes were dissected from the Transwells with a small diamond knife and flat embedded in pure epon 812 . Ultrathin sections were stained with uranyl acetate and lead nitrate. The sections were examined with a JEOL 1200 EX/II electron microscope (Tokyo, Japan) at $60 \mathrm{kV}$.

\section{TNF- $\alpha$ and LPS treatment}

Dilutions of TNF- $\alpha(50,500 \mathrm{pg} / \mathrm{ml}$ and $10 \mathrm{ng} / \mathrm{ml})$ or LPS $(50,500 \mathrm{ng} / \mathrm{ml}$ and $10 \mu \mathrm{g} / \mathrm{ml})$ were prepared in complete medium. In the LPS experiments, medium containing $20 \%$ normal human serum was used instead of heat-inactivated human and calf sera. At the start of the experiment $0.5 \mathrm{ml}$ of TNF- $\alpha$ - or LPScontaining medium was added to the upper compartment of the chamber. After overnight incubation at $37^{\circ} \mathrm{C}$, the permeability of the monolayers was determined.

\section{Permeability studies}

For the detection of macromolecular passage across the membranes, a tracer solution containing both FITC-labelled BSA $(250 \mu \mathrm{g} / \mathrm{ml})$ and RITC-labelled dextran $(250 \mu \mathrm{g} / \mathrm{ml})$ was prepared in complete medium. In the upper compartment, culture medium was replaced by $0.5 \mathrm{ml}$ of the tracer solution, while the lower volume was refreshed with $1.5 \mathrm{ml}$ complete medium. After 1, 6 and $24 \mathrm{~h}$ of diffusion, $250 \mu \mathrm{l}$ samples were drawn from the lower compartment, which was replenished with an equal volume fresh medium each time. The collected samples were diluted with $1 \mathrm{ml}$ PBS and the concentrations of FITCBSA and RITC-DEX were measured using a Hitachi 5000 fluorophotospectrometer, at emission/excitation wavelengths of $495 / 520 \mathrm{~nm}$ and $560 / 580 \mathrm{~nm}$, respectively. The albumin and dextran concentrations in the samples were calculated using linear regression of a diluted series of the tracer.

\section{Statistical analysis}

Differences between permeability to albumin and dextran were calculated by paired Student t-test. In order to control for the different membrane types used in our studies, the permeability of untreated HUVEC monolayers was calculated as a ratio of the corresponding unseeded membranes. Similarly, the effect of treatment of monolayers on different membranes was compared to control monolayers cultured on corresponding membranes. Differences between permeability ratios were calculated by KruskallWallis non-parametric ANOVA.

\section{Results}

\section{Permeability of membranes with different} protein coatings and without seeded cells

Membranes coated with collagen, fibronectin or gelatin showed significantly different permeability rates. The diffusion of both albumin and dextran occurred faster across the collagen-coated membranes than across the fibronectin or gelatin-coated membranes (Fig. 1). Permeability to albumin and dextran appeared to be essentially the same, although average dextran concentrations in the lower compartment were almost invariably slightly less than albumin concentrations. However, during the permeability assay this difference never reached statistical significance.

After $1 \mathrm{~h}$ of diffusion, the concentrations of albumin and dextran in the lower compartment of the collagen-coated membrane inserts were $11.2 \pm$ $4.5 \mu \mathrm{g} / \mathrm{ml}$ and $10.1 \pm 4.4 \mu \mathrm{g} / \mathrm{ml}$, respectively. This accounted for approximately $17 \%$ of the calculated equilibrium concentration of $62.5 \mu \mathrm{g} / \mathrm{ml}$. Significantly less albumin and dextran accumulated in the lower compartment of the gelatin- or fibronectin-coated membranes, both allowing less than $2 \mu \mathrm{g} / \mathrm{ml}$ during the first hour, or about $5 \%$ of the calculated equilibrium concentration. At the end of the assay, after $24 \mathrm{~h}$, these differences were still significant, although less explicit: the tracer concentration in the lower compartment of the collagen-coated membrane inserts were $49.4 \pm 4.3 \mu \mathrm{g} / \mathrm{ml}$ (for albumin) and $46.4 \pm$ $4.9 \mu \mathrm{g} / \mathrm{ml}$ (for dextran), while less than $34 \mu \mathrm{g} / \mathrm{ml}$ of either molecule had accumulated in the lower compartment of the fibronectin or gelatin-coated membrane inserts. 


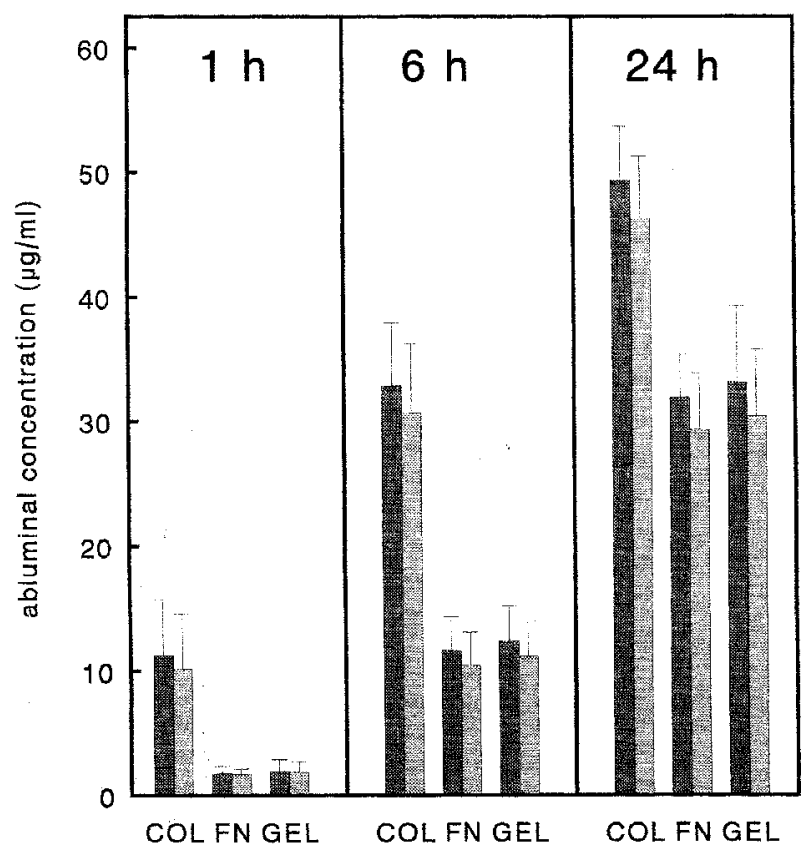

FIG. 1. Permeability of Transwell culture inserts for FITCalbumin and RITC-dextran. Bars represent the abluminal concentration in $\mu \mathrm{g} / \mathrm{ml}$ of permeated albumin (hatched bars) and dextran (filled bars) after 1 (left panel), 6 (middle panel) and 24 (right panel) $h$ of equilibration. Data represent at least four independent measurements originating from two or more experiments and are expressed as mean \pm SD. Culture inserts: $\mathrm{COL}=$ collagen coated, $\mathrm{FN}=$ fibronectin coated, GEL = gelatin coated.

\section{Permeability of HUVEC monolayers}

Culturing of HUVEC for six days resulted in the growth of confluent monolayers that had formed tight junctions throughout the culture. As shown in Fig. 2, these junctions were present between cells grown on all three different matrix proteins. On all membranes the permeability to albumin and dextran was significantly restricted by HUVEC monolayers (Fig. 3). Although monolayers cultured on collagen-coated PTFE membranes allowed more albumin and dextran passage than monolayers cultured on gelatin-or fibronectin-coated PE membranes, comparing the permeability to the corresponding unseeded membranes showed that the relative restriction to albumin and dextran by HUVEC monolayers was similar for the three coatings. For instance, after $1 \mathrm{~h}$, monolayers cultured on collagen, fibronectin or gelatin reduced passage of albumin by $87.0 \pm 4.8 \%(n=12), 79.8 \pm 5.6 \%(n=$ $4)$ or $82.2 \pm 4.7 \%(n=4)$, respectively, when compared to the permeability of unseeded membranes. After $24 \mathrm{~h}$, these percentages were $55.5 \pm$ $7.2,61.7 \pm 1.9$ and $59.3 \pm 8.2$, respectively. Similar data could be calculated for the dextran permeability, but the relative restriction was not significantly different between the three coatings.
In order to investigate whether the extracellular matrix, produced by the cells during culture, differently contributed to the permeability after initial seeding on either protein, HUVEC were grown for six days and the permeability was measured. Thereafter, the cells were lysed, leaving membranes with matrix (coating plus the extracellular matrix laid down by the cells) only and the permeability was measured again. After cell lysis, albumin permeability measured after $1 \mathrm{~h}$ of diffusion was increased by a factor $4.4 \pm$ $0.8(n=4)$ on collagen-coated membranes, $4.9 \pm 0.1$ on fibronectin-coated membranes and $4.5 \pm 0.1$ on gelatin-coated membranes. Dextran permeability changed accordingly, but as with albumin, the permeability increase after cell lysis did not significantly differ between the collagen-, gelatin- and fibronectincoated membranes.
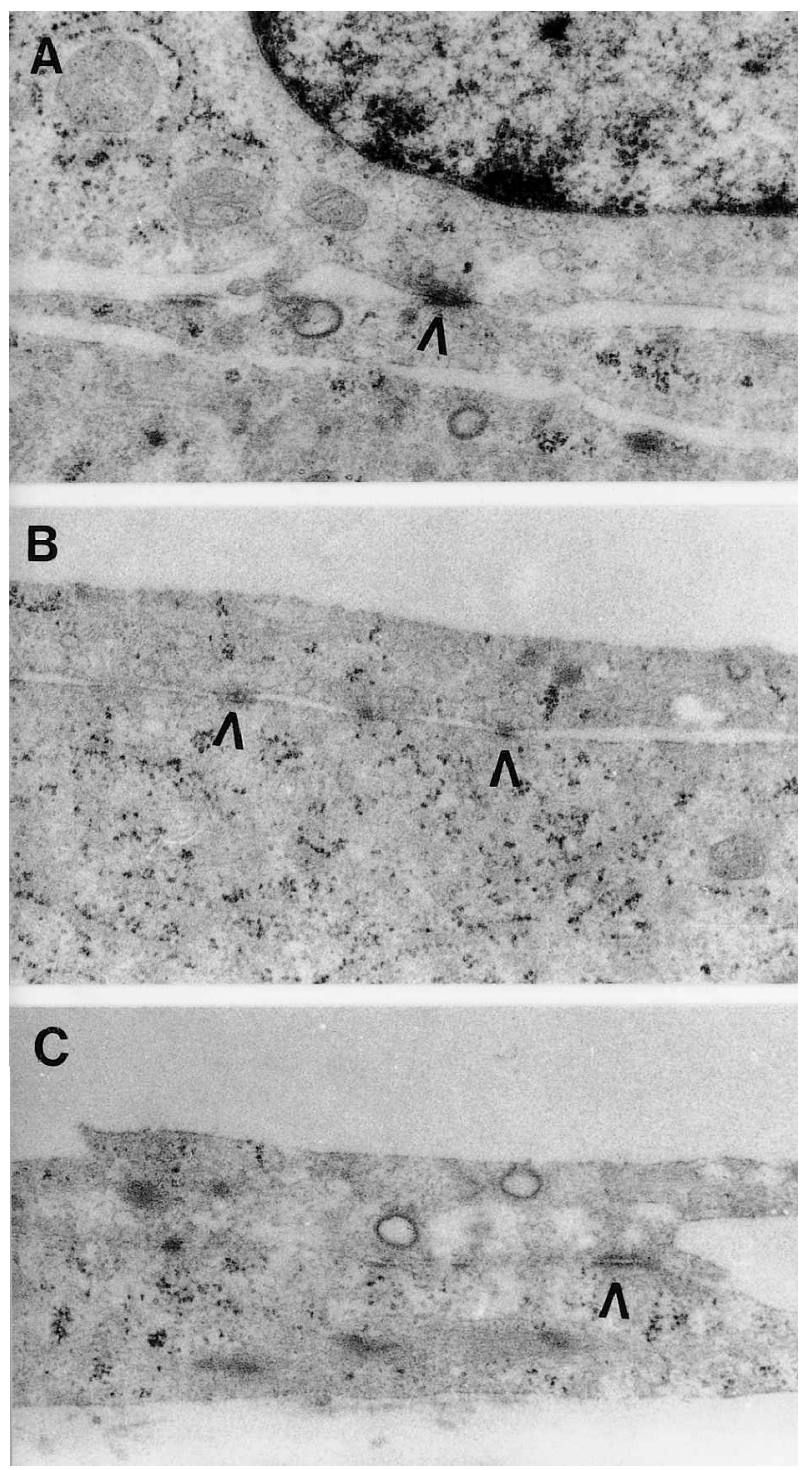

FIG. 2. Ultramorphologic characteristics of HUVEC monolayers cultured on different matrices. HUVEC cultured on (A) collagen- (B) fibronectin- and (C) gelatin-coated membranes. Note junctional complexes between adjacent cells (arrowheads). Magnification 30,000×. 


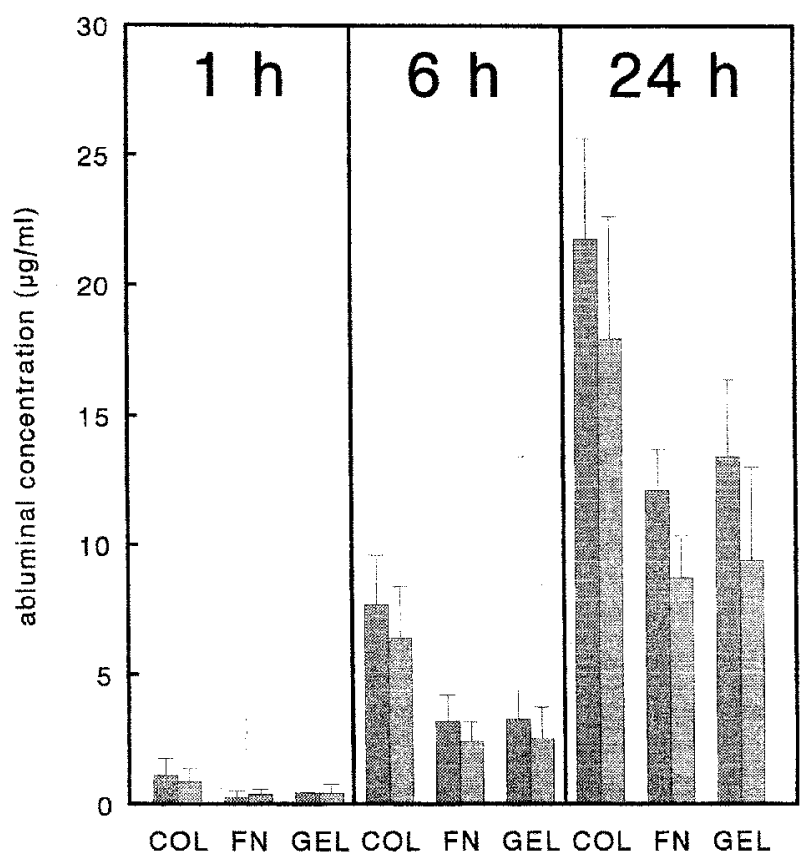

FIG. 3. Permeability of HUVEC monolayers cultured on collagen, fibronectin and gelatin. Bars represent the abluminal concentration in $\mu \mathrm{g} / \mathrm{ml}$ of permeated albumin (hatched bars) and dextran (filled bars) in time (cf. legend to Fig. 1). Data represent at least four independent measurements originating from two or more experiments and are expressed as mean \pm SD.

\section{Permeability of TNF- $\alpha$ or LPS-pretreated HUVEC monolayers}

Pre-incubation of the monolayers with increasing doses of TNF- $\alpha$ or LPS resulted in a dose-dependent increase in monolayer permeability. In order to allow a quantitative comparison of the effects induced by these inflammatory mediators on the monolayers grown on the different coatings, permeability was expressed as the ratio between treated and untreated monolayers. While a dose of $50 \mathrm{pg} / \mathrm{ml}$ of TNF- $\alpha$ was insufficient to enhance the permeability for albumin, a dose of $500 \mathrm{pg} / \mathrm{ml}$ of TNF- $\alpha$ induced a moderate permeability increase of the monolayers cultured on collagen, fibronectin or gelatin (Fig. 4A). A further stimulation was observed at a concentration of $10 \mathrm{ng} /$ $\mathrm{ml}$ TNF- $\alpha$. After $1 \mathrm{~h}$ of diffusion, the relative increase ranged from $2.0 \pm 0.4$ (on gelatin) to $2.3 \pm 0.2$ (on collagen). The TNF- $\alpha$ effect could be observed on all the coatings and no significant differences were observed between monolayers cultured on either collagen, gelatin or fibronectin. After 6 and $24 \mathrm{~h}$ of diffusion, the permeability difference between TNF- $\alpha$ treated monolayers and control monolayers gradually declined, resulting in a ratio close to 1 . Still, at the highest dose the effect seemed persistent for at least $24 \mathrm{~h}$ : at this time the ratio between treated and nontreated monolayers ranged between $1.2 \pm 0.2$ (on collagen) to $1.3 \pm 0.04$ (on gelatin). A similar picture emerged for the permeability to dextran (Fig. 4B).
Pre-incubation with bacterial LPS also induced a dose-dependent increase in permeability which, like in the TNF- $\alpha$ experiments, seemed qualitatively and quantitatively independent of the protein on which the monolayers were initially cultured. However, the enhanced permeability seemed less persistent after LPS pre-incubation than after pre-incubation withTNF$\alpha$. After $1 \mathrm{~h}$ of diffusion, $500 \mathrm{ng} / \mathrm{ml}$ LPS had induced an albumin permeability which was a factor $1.2 \pm 0.2$ (on fibronectin) to $1.5 \pm 0.3$ (on collagen) higher than the permeability in untreated monolayers (Fig. 5A). At $10 \mu \mathrm{g} / \mathrm{ml}$ LPS a further increase was observed ranging from a factor $1.9 \pm 0.7$ (on gelatin) to $2.3 \pm 0.2$ (on collagen). Similar values were obtained from dextran measurements (Fig. 5B). However, during further incubation of albumin and dextran on LPS-treated monolayers a rapid decline towards control monolayer permeability was observed, reaching a ratio after 6 and $24 \mathrm{~h}$ that was not significantly different from 1 .

\section{Discussion}

We have investigated the influence of different, but commonly used, matrix protein substrates on the permeability of resting, and TNF- $\alpha$ - or LPS-treated HUVEC monolayers and found no essential differences between cells seeded on collagen, fibronectin or gelatin.

$1 \mathrm{~h}$

$6 \mathrm{~h}$

$24 \mathrm{~h}$

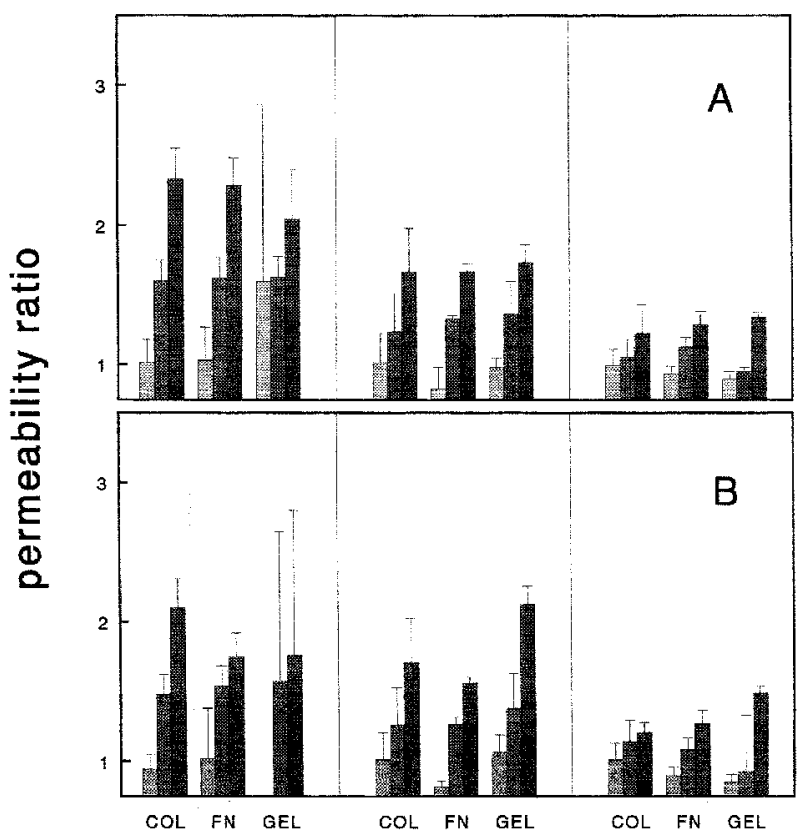

FIG. 4. Permeability of TNF- $\alpha$-treated HUVEC monolayers. The increase in permeability to albumin (panel A) and dextran (panel $B$ ) is expressed as the permeability ratio ( \pm $\mathrm{SD}, n=4$ ) between treated and untreated monolayers. In panels, from left to right, the permeability ratio of monolayers cultured on collagen (COL), fibronectin (FN) and gelatin (GEL), after 1, 6 and $24 \mathrm{~h}$ of diffusion is shown. Open bars: $50 \mathrm{pg} / \mathrm{ml} \mathrm{TNF}-\alpha$; grey bars: $500 \mathrm{pg} / \mathrm{ml}$ TNF- $\alpha$; black bars: $10 \mathrm{ng} / \mathrm{ml}$ TNF- $\alpha$. 


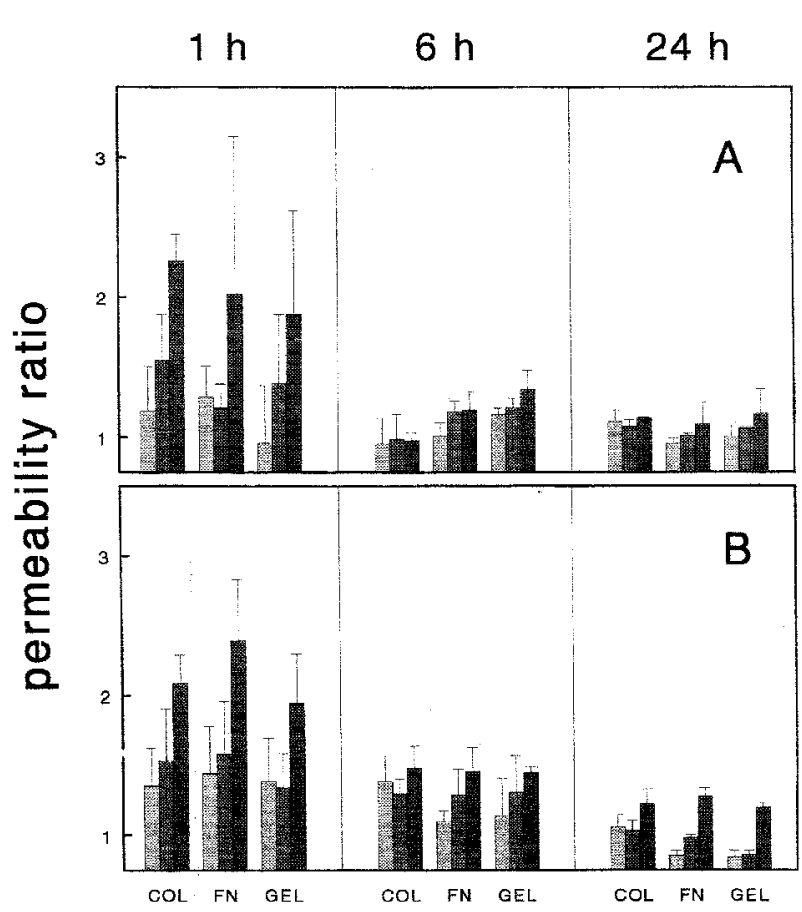

FIG. 5. Permeability of LPS-treated HUVEC monolayers. The increase in permeability to albumin (panel A) and dextran (panel $B)$ is expressed as the permeability ratio $( \pm S D, n=4)$ between treated and untreated monolayers. In panels, from left to right, the permeability ratio of monolayers cultured on collagen (COL), fibronectin (FN) and gelatin (GEL), after 1, 6 and $24 \mathrm{~h}$ of diffusion is shown. Open bars: $50 \mathrm{ng} / \mathrm{ml}$ LPS; grey bars: $500 \mathrm{ng} / \mathrm{ml}$ LPS; black bars: $10 \mu \mathrm{g} / \mathrm{ml}$ LPS.

One could think of several reasons for such a difference to exist. The attachment and growth of endothelial cells in vitro depends at least in part on specific binding sites provided by the ECM. Also, the ECM is involved in mechanisms by which inflammatory mediators cause increased endothelial permeability and loss of monolayer integrity. These receptormediated mechanisms include: disruption of cell-cell contacts by cytoskeletal and/or junctional reorganization and alteration of endothelial adhesion molecule expression, ${ }^{24}$ disruption of cell-matrix contacts by altering endothelial matrix receptor expression and loss of cell attachments sites in the $\mathrm{ECM} ;{ }^{25}$ disruption of matrix-matrix contacts by proteolytic degradation and remodelling of the ECM. ${ }^{16}$ Despite the apparent contribution of ECM proteins on endothelial permeability, different ECM proteins, as well as mixtures of ECM proteins, have been used for endothelial cell culturing.

For the evaluation of endothelial monolayer permeability, multi-well culture inserts suited with microporous membranes were used in this study. A major advantage of these culture inserts is that they allow an easy and multiple analysis of monolayer permeability, with only minor modifications of the standard culture conditions. Moreover, these inserts all allowed visual examination of the monolayer before and after the permeability assay. Across unseeded membranes, the accumulation of albumin appeared always slightly faster than that of dextran. Physical properties, like shape, diameter and charge, of these molecules could be responsible for this difference. Untreated cultured HUVEC monolayers, and TNF- $\alpha$ - or LPS-treated monolayers, did not show a clear preference for the passage of either albumin or dextran. Since albumin passage occurs by both active vesicular and paracellular transport, while dextran only passively diffuses through the intercellular clefts, ${ }^{9,26}$ we conclude that in our experiments diffusion via the transcellular route contributes less to the permeability of resting and activated monolayers and that the majority of albumin and dextran pass the endothelial monolayer by means of the paracellular route.

HUVEC monolayers cultured on collagen-, fibronectin- or gelatin-coated membranes did not display different morphologic characteristics, as was revealed by light and transmission electron microscopy. All monolayers displayed typical cobblestone morphology and tight junctions were abundantly present between neighbouring cells. Confluence was usually achieved within six days and was independent of the type of coating used. In the permeability experiments all differences observed between the monolayers cultured on the three proteins could be attributed to the original differences observed in the unseeded filters. Thus, collagen, fibronectin and gelatin are all suitable as a substrate for the attachment and growth of endothelial cells in vitro, and in our model, these substrates do not induce different responses to inflammatory mediators. We assume that additional ECM proteins, produced by the endothelial cells and laid down into the ECM, mediate most of the endothelial-ECM interactions involved in monolayer permeability. The production of ECM proteins, including fibronectin, laminin and type IV collagen, by endothelial cells in vitro has been previously shown by others. ${ }^{27}$ In our experiments we did not see a difference in the membrane permeability changes induced by a procedure which removed the cells while leaving the ECM on the membrane. Although the eventual composition of the ECM may differ between monolayers cultured on collagen, fibronectin and gelatin, its contribution to the permeability of untreated and TNF- $\alpha$ or LPSHUVEC monolayers apparently is of minor significance. When the monolayers were exposed to TNF$\alpha$, a dose-dependent increase of permeability was observed, which is in accordance with previous observations. ${ }^{20}$ Although loss of fibronectin has been associated with a TNF- $\alpha$-mediated increase of permeability, ${ }^{12}$ we did not observe a difference between monolayers cultured on collagen-, fibronectin- or gelatin-coated membranes. Possibly, in our experiments TNF- $\alpha$ treatment did not induce significant matrix degradation or matrix degradation equally affected the three ECM proteins investigated. 
When compared to TNF- $\alpha$, LPS pre-treatment resulted in a moderate and more transient increase of permeability, suggesting that continuous exposure of LPS may be required for a prolonged permeability enhancement. Others have shown that the effect of LPS on endothelial permeability depends on the availability of soluble CD14 and lipopolysaccharide binding protein in serum. ${ }^{28}$ Further studies are needed to reveal eventual differences between TNF- $\alpha$ and LPS-induced endothelial permeability and the reversibility of these changes.

In conclusion, we have demonstrated that cultured HUVEC monolayers seeded on various proteins are equally suitable as a model for vascular permeability, showing physiologically relevant responses to inflammatory stimuli. Apparently, the initial differences in cellular environment are unimportant with respect to the eventual permeability characteristics of the confluent monolayer, possibly as a result of additional ECM laid down during culture.

\section{References}

1. Davies MG, Hagen PO. Systemic inflammatory response syndrome. $B r J$ Surg 1997; 84: 920-35.

2. Bradley JR, Wilks D, Rubenstein D. The vascular endothelium in septic shock. J Infec 1994; 28: 1-10.

3. Garcia JG, Verin AD, Schaphorst KL. Regulation of thrombin-mediated endothelial cell contraction and permeability. Semin Thromb Hemost 1996; 22: 309-15.

4. Boyle EM, Pohlman TH, Johnson MC, Verrier ED. Endothelial cell injury in cardiovascular surgery. The systemic inflammatory response. Ann Thorac Surg 1997; 63: 277-84.

5. Cooper JA, Del Vecchio PJ, Minnear FL, Burhop KE, Selig WM, Garcia JG, Malik AB. Measurement of albumin permeability across endothelial monolayers in vitro. J Appl Physiol 1987; 62: 1076-83.

6. Kazakoff PW, McGuire TR, Hoie EB, Cano M, Iversen PL. An in vitro model for endothelial permeability: assessment of monolayer integrity. In Vitro Cell Dev Biol - An. 1995; 31: 846-52.

7. Ehringer WD, Edwards MJ, Miller FN. Mechanisms of alpha-thrombin, histamine, and bradykinin induced endothelial permeability. J Cell Physiol 1996; 167: 562-9.

8. Conforti G, Dominguez-Jiminez C, Ronne E, Hoyer-Hansen G, Dejana E. Cell-surface plasminogen activation causes retraction of in vitro cultured human umbilical vein endothelial cell monolayer. Blood 1994; 83: 994-1005.

9. Tiruppathi C, Song W, Bergenfeldt M, Sass P, Malik AB. Gp60 activation mediates albumin transcytosis in endothelial cells by tyrosine kinasedependent pathway. J Biol Chem 1997; 272: 25968-75.

10. Gulino D, Delachanal E, Concord E, Genoux Y, Morand B, Valiron MO, Sulpice E, Scaife R, Alemany M, Vernet T. Alteration of endothelial cell monolayer integrity triggers resynthesis of vascular endothelium cadherin. J Biol Chem 1998; 273: 29786-93.
11. Bannerman DD, Sathyamoorthy M, Goldblum SE. Bacterial lipopolysaccharide disrupts endothelial monolayer integrity and survival signalling events through caspase cleavage of adherens junction proteins. $J$ Biol Chem 1998; 273: 35371-80.

12. Partridge CA, Horvath CJ, Del Vecchio PJ, Phillips PG, Malik AB. Influence of extracellular matrix in tumor necrosis factor-induced increase in endothelial permeability. Am J Physiol 1992; 263: L627-33.

13. Curtis TM, McKeown Longo PJ, Vincent PA, Homan SM, Wheatley EM, Saba TM. Fibronectin attenuates increased endothelial monolayer permeability after RGD peptide, anti-alpha 5 beta 1 , or TNF-alpha exposure. $A m$ J Physiol 1995; 269: L248-60.

14. Wheatley EM, Vincent PA, McKeown Longo PJ, Saba TM. Effect of fibronectin on permeability of normal and TNF-treated lung endothelial cell monolayers. Am J Physiol 1993; 264: R90-6.

15. Defilippi P, Silengo L, Tarone G. Alpha 6:beta 1 integrin (laminin receptor) is down-regulated by tumor necrosis factor alpha and interleukin-1 beta in human endothelial cells. J Biol Chem 1992; 267: 18303-7.

16. Partridge CA, Jeffrey JJ, Malik AB. A $96-\mathrm{kDa}$ gelatinase induced by TNFalpha contributes to increased microvascular endothelial permeability. Am J Physiol 1993; 265: L438-47.

17. Dejana E. Endothelial adherens junctions: Implications in the control of vascular permeability and angiogenesis. J Clin Invest 1996; 98: 1949-53.

18. Albelda SM, Sampson PM, Haselton FR, McNiff JM, Mueller SN, Williams SK et al. Permeability characteristics of cultured endothelial cell monolayers. J Appl Pbysiol 1988; 64: 308-22.

19. Meyrick BO, Ryan US, Brigham KL. Direct effects of $E$ coli endotoxin on structure and permeability of pulmonary endothelial monolayers and the endothelial layer of intimal explants. Am J Pathol 1986; 122: 140-51.

20. Royall JA, Berkow RL, Beckman JS, Cunningham MK, Matalon S, Freeman BA. Tumor necrosis factor and interleukin 1 alpha increase vascular endothelial permeability. Am J Physiol 1989; 257: L399-410.

21. IshiiY, ShuyiW, Kitamura S. Soluble CD14 in serum mediates LPS-induced increase in permeability of bovine pulmonary arterial endothelial cell monolayers in vitro. Life Sci 1995; 56: 2263-72.

22. Kusama T, Kohno H, Idezawa T, Fujii H, Yamamoto M, Matsumoto Y. Inhibition of tumor necrosis factor alpha-induced vascular endothelial permeability by gadolinium chloride. Eur Surg Res 1997; 29: 375-81.

23. Jaffe EA, Nachman RL, Becker CG, Minick CR. Culture of human endothelial cells derived from umbilical veins. Identification by morphologic and immunologic criteria. J Clin Invest 1973; 52: 2745-56.

24. Dejana E, Corada M, Lampugnani MG. Endothelial cell-to-cell junctions. FASEB J 1995; 9: 910-18.

25. Lampugnani MG, Corada M, Caveda L, Breviario F, Ayalon O, Geiger B, Dejuna E. The molecular organization of endothelial cell to cell junctions: differential association of plakoglobin, beta-catenin, and alpha-catenin with vascular endothelial cadherin (VE-cadherin).J Cell Biol 1995; 129: 203-17.

26. Ghitescu L, Bendayan M. Transendothelial transport of serum albumin: a quantitative immunocytochemical study. J Cell Biol 1992; 117: 745-55.

27. Yao J, Bone RC, Sawhney RS. Differential effects of tumor necrosis factor-alpha on the expression of fibronectin and collagen genes in cultured bovine endothelial cells. Cell Mol Biol Res 1995; 41: 17-28.

28. Goldblum SE, Brann TW, Ding X, Pugin J, Tobias PS. Lipopolysaccharide (LPS)-binding protein and soluble CD14 function as accessory molecules for LPS-induced changes in endothelial barrier function, in vitro. J Clin Invest 1994; 93: 692-702.

\section{Received 18 August 2000; accepted 9 October 2000}




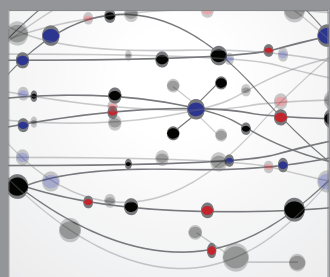

The Scientific World Journal
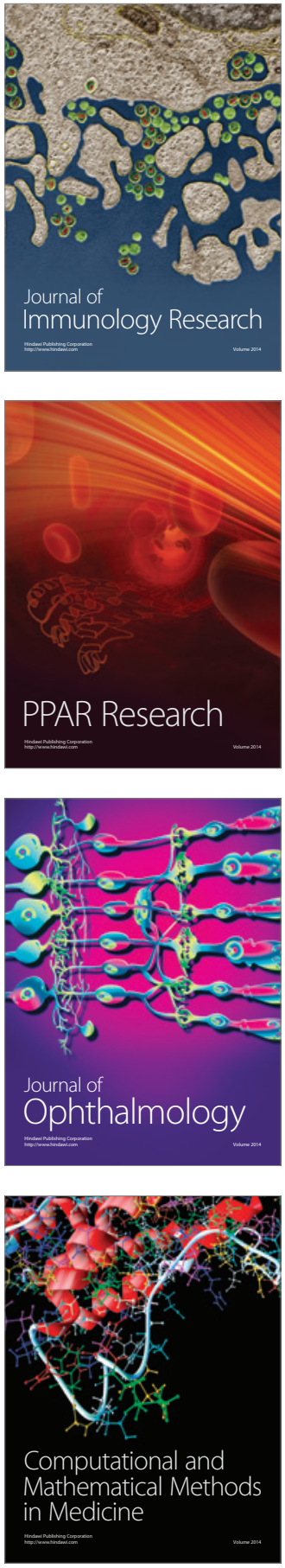



Gastroenterology

Research and Practice
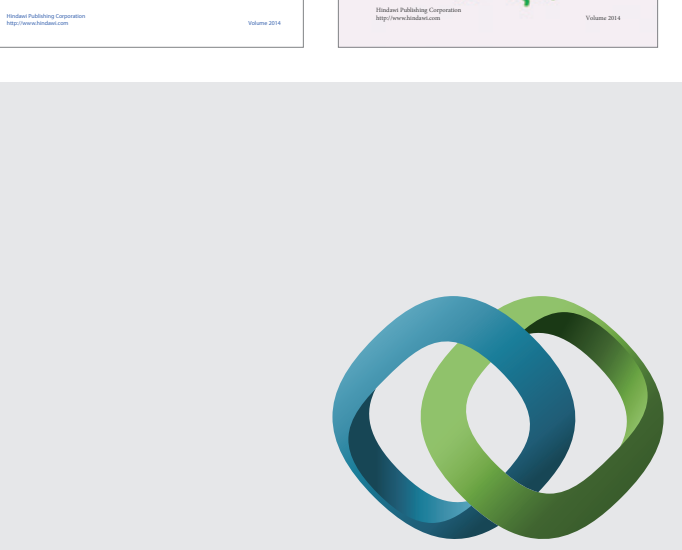

\section{Hindawi}

Submit your manuscripts at

http://www.hindawi.com
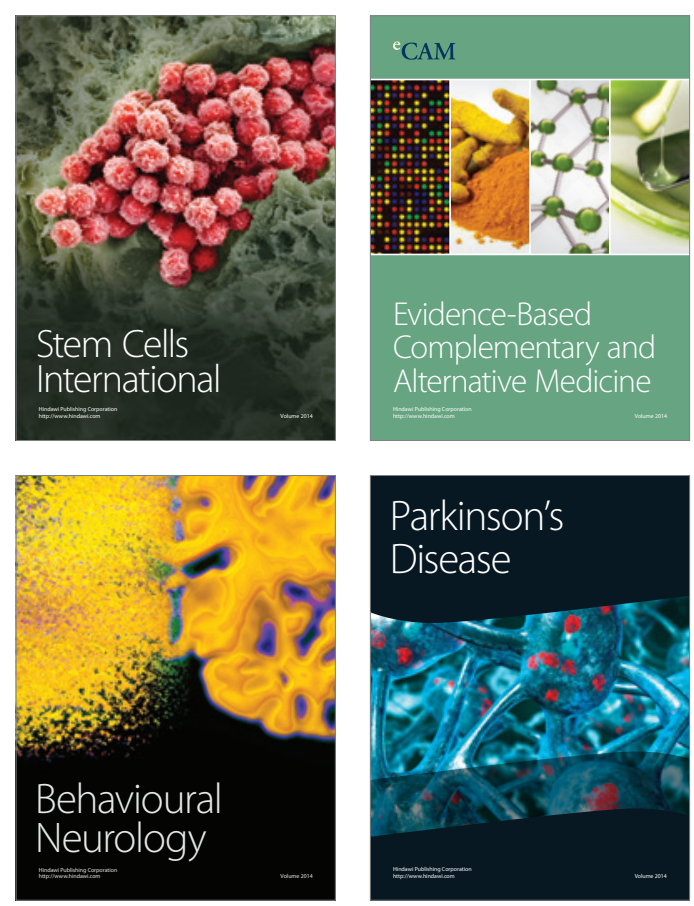

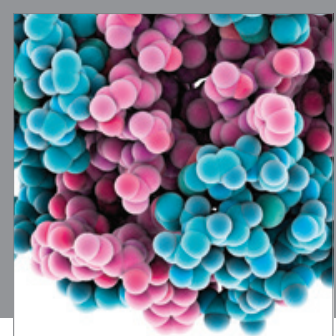

Journal of
Diabetes Research

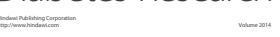

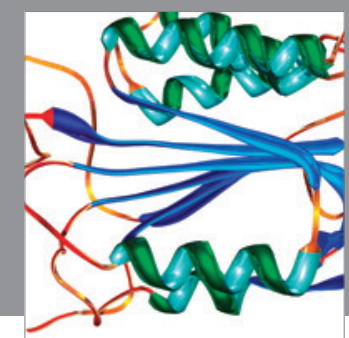

Disease Markers
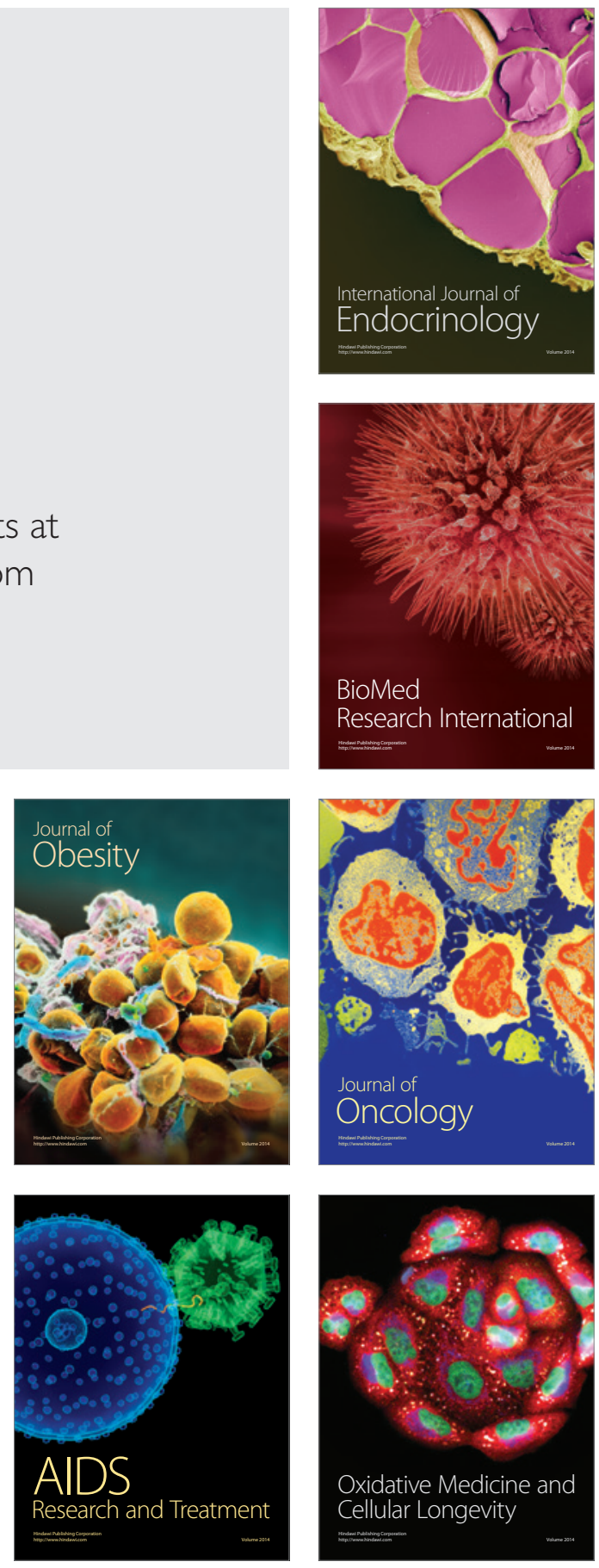